\title{
Susbtituição do ligamento cruzado cranial por segmento teno-ósseo homólogo conservado em glicerina a 98\%. Estudo experimental em cães
}

\author{
Substitution of cranial cruciate ligament in dogs by homologous bone-tendon segment preserved in $98 \%$ \\ glycerin. Experimental study in dogs
}

\begin{abstract}
Fabiano Zanini Salbego ${ }^{\mathrm{I}}$ Alceu Gaspar Raiser ${ }^{\mathrm{II}}$ Alexandre Mazzanti ${ }^{\mathrm{II}}$ Ney Luiz Pippi ${ }^{\mathrm{II}}$ Dominguita Lurhs Graça $^{\text {III }}$ Soraia Figueiredo de Souza ${ }^{\mathrm{I}}$ Charles Pelizzari ${ }^{\mathrm{I}}$ Rafael Festugatto ${ }^{\mathrm{I}}$ Diego Vilibaldo Beckmann ${ }^{\mathrm{IV}}$ Lucilene Bernardi de Souza ${ }^{\mathrm{IV}}$ Marina Mori da Cunha ${ }^{\mathrm{IV}}$ Ana Paula da Silva ${ }^{\mathrm{IV}}$

Rosmarini Passos dos Santos ${ }^{\mathrm{IV}}$
\end{abstract}

\section{RESUMO}

Na presente pesquisa, foram utilizados implantes teno-ósseos homólogos conservados em glicerina a 98\%, na reparação do ligamento cruzado cranial, em 24 cães adultos pesando entre 15 e $30 \mathrm{~kg}$. Os implantes foram passados por um leito receptor preparado no fêmur e outro na tíbia e ancorados por meio de fios de poliéster em parafusos fixados respectivamente nas extremidades distal e proximal desses ossos. A articulação do joelho foi imobilizada por um período de 30 dias. Os animais foram distribuídos em dois grupos para as avaliações radiográfica, macroscópica e histológica do implante aos 60 dias (grupo B) e aos 90 dias (grupo A) de evolução pós-operatória. Em nenhum dos cães, houve evidência de fragilização do implante ou evidência radiográfica ou macroscópica de degeneração articular até os 90 dias de pósoperatório.

Palavras-chave: ligamento cruzado cranial, implante, cão, ortopedia.

\section{ABSTRACT}

In the present study, homologue bone-tendon implants conserved in 98\% glycerin were used in the restoration of the cranial cruciate ligament in 24 adult dogs weighing between 15 and $30 \mathrm{~kg}$. The implants were placed in a stratified layer prepared in the femur and the tibia and anchored with polyester filament fastened to the distal and proximal extremities of these bones, respectively. The knee joint was immobilized for a period of 30 days. The animals were distributed into two groups for radiographic, macroscopic and histological evaluation of the implant at 60 days after the operation for group $B$ and at 90 days for group A. There was no evidence in any of the dogs of fragility of the implant, nor radiographic or macroscopic evidence of joint degeneration up to 90 days post-operative.

Key words: cruciate ligament; implant, dog, orthopedic.

\section{INTRODUÇÃO}

A ruptura do ligamento cruzado cranial (LCCr) é uma das lesões mais comuns no cão, gerando instabilidade na articulação fêmuro-tíbio-patelar (AFTP), podendo ocasionar osteoartrose e lesões dos meniscos (BRINKER et al., 1999; ARNOCZKY, 1996; VASSEUR, 1998).

Para permitir sua reconstrução, vários substitutos já foram utilizados, sendo o enxerto autólogo teno-ósseo o mais empregado em humanos (FU \& SCHULTE, 1996). Entretanto, esse procedimento não é totalmente inócuo (ZEKCER et al., 2001), pois diminui a força extensora (TIBONE \& ARTRICH, 1998), causa dor na região caudal do joelho (MAEDA et al., 1996), limita o movimento extensor (JACKSON \& SHALFER, 1990) e causa tendinite patelar e contratura infrapatelar (ANDRADE et al., 1999), além da mutilação parcial na área doadora. Os implantes homólogos determinam vantagens em relação ao enxerto autógeno como menor morbidade e menor tempo cirúrgico (ANDRADE et al., 1999; PACCOLA et al., 2000).

O presente experimento tem por objetivo avaliar o uso de um segmento teno-ósseo homólogo conservado em glicerina a 98\%, para substituir o ligamento cruzado cranial em cães. O uso de um implante homólogo conservado diminuirá a morbidade relacionada ao comprometimento da patela e de seu ligamento, constituindo uma alternativa cirúrgica à

IPrograma de Pós-graduação em Medicina Veterinária (PPGMV), Universidade Federal de Santa Maria (UFSM). 971105-900, Santa Maria, RS, Brasil. E-mail: fabianosalbego@yahoo.com.br Autor para correspondência.

IIDepartamento de Clínica de Pequenos Animais (DCPA), Centro de Ciências Rurais (CCR), UFSM, Santa Maria, RS, Brasil.

IIIDepartamento de Patologia, UFSM, Santa Maria, RS, Brasil.

${ }^{\mathrm{IV}}$ Curso de Medicina Veterinária, CCR, UFSM, Santa Maria, RS, Brasil. 
técnica utilizada em humanos, que utiliza enxerto autólogo, mas não foi relatada para cães.

\section{MATERIAL E MÉTODOS}

Foram utilizados 24 cães, sem raça definida, pesando entre 15 e $30 \mathrm{~kg}$, com idade superior a dois anos, separados aleatoriamente em dois grupos de igual número, A e B, e submetidos à substituição do ligamento cruzado cranial por segmento teno-ósseo homólogo, conservado em glicerina a $98 \%$ por um período mínimo de 30 dias. O implante foi colhido de cadáveres de cães com peso variando entre 5 e 15kg, livres de doenças infecto-contagiosas, processos neoplásicos ou alterações estruturais envolvendo a AFTP, e consistiu da patela, do tendão patelar e da tuberosidade da tíbia (Figura 1A).

O implante foi submetido à reidratação em solução isotônica estéril de cloreto de sódio a 0,9\% acrescida de iodo povidine na proporção de 50:1 nas 24 horas que antecederam a implantação. Cerca de 30 minutos antes do procedimento cirúrgico, cada animal de experimentação recebeu cefalotina sódica (30 $\mathrm{mg} \mathrm{kg}^{-1}$, IV), que foi suplementada após duas horas de transoperatório. Cada cão foi pré-medicado com sulfato de atropina ( $\left.0,44 \mathrm{mg} \mathrm{kg}^{-1}\right)$, associado na mesma seringa a sulfato de morfina $\left(1,0 \mathrm{mg} \mathrm{kg}^{-1}\right)$ ambos por via intramuscular. A anestesia foi induzida com propofol $\left(6,0 \mathrm{mg} \mathrm{kg}^{-1}\right)$ e mantida com halotano vaporizado em oxigênio; a analgesia transoperatória foi assegurada com citrato de fentanila $\left(0,002 \mathrm{mg} \mathrm{kg}^{-1}\right)$ administrado a cada 30 minutos.

Imediatamente antes da abordagem articular, o implante foi moldado e foram efetuadas duas perfurações, com auxílio de um fio de Kirschner de 0,8mm e de uma furadeira, em cada um de seus segmentos ósseos (patela e tuberosidade tibial), sem produzir sua fragilização, por onde foram inseridos $20 \mathrm{~cm}$ de fio de poliéster trançado siliconizado n. 0 (Figura 1A).

Após acesso crânio-lateral à articulação do joelho, o LCCr foi medido com auxílio de um paquímetro analógico, mantendo-se a AFTP em angulação de $30^{\circ}$, e removido por secção com bisturi junto a suas inserções. No fêmur, foi preparado um leito receptor, com auxílio de uma broca de 8,0mm de diâmetro acoplada a uma furadeira de baixa rotação, que iniciou no local de origem do LCCr e terminou no côndilo lateral. Na tíbia, foi preparado outro leito, que iniciou no ponto isométrico entre a tuberosidade e o platô medial e terminou medial à tuberosidade tibial. A seguir, foram inseridos dois parafusos com arruelas, um deles proximal ao côndilo lateral do fêmur e outro distal à tuberosidade tibial, em sua face medial. O segmento teno-ósseo foi então implantado (Figura 1B) mediante passagem dos fios de poliéster pelos leitos receptores (patela no fêmur, tuberosidade na tíbia), de modo que as porções ósseas ficassem dentro deles e os fios emergentes fossem atados aos parafusos pré-fixados. A fixação do implante no leito receptor foi realizada com a articulação posicionada em ângulo de $140^{\circ}$, confirmada com o uso de um goniômetro. Após isso, a AFTP foi posicionada em ângulo de $30^{\circ}$ e a porção ligamentar do implante, no espaço articular, foi aferida com auxílio de um paquímetro, visando à comparação entre esta medida e aquela efetuada no ligamento original. Posteriormente, a articulação foi irrigada com solução salina isotônica e os planos anatômicos reconstituídos com poliglactina $910 \mathrm{n}$. 2-0 em padrão de Sultan, e a pele com fio mononáilon 4-0 em pontos simples isolados. Ao final do procedimento, a articulação foi imobilizada por quatro semanas, pelo

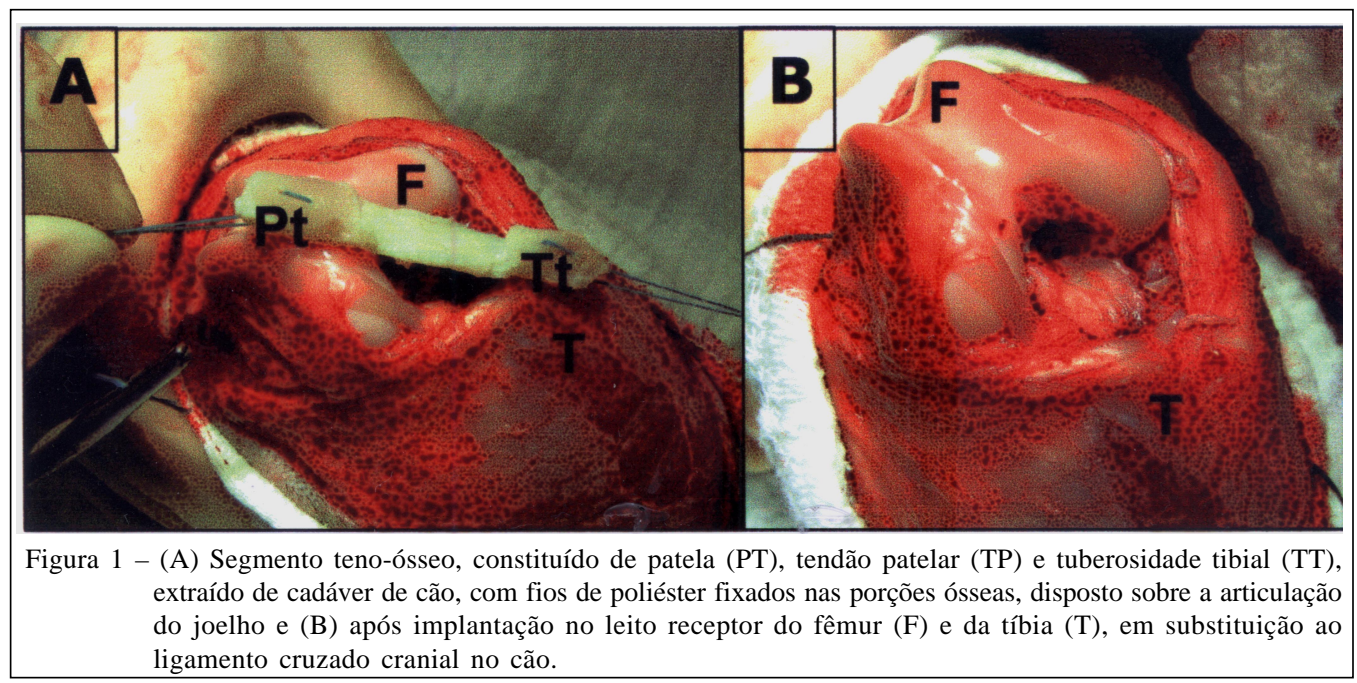

Ciência Rural, v.37, n.2, mar-abr, 2007. 
método de transfixação percutânea (Ehmer-Kirschner). No período pós-operatório, manteve-se analgesia opióide (morfina) por dois dias e antiinflamatório não esteróide por mais três dias.

A instabilidade articular foi avaliada (movimento de gaveta) após a fixação do implante e o fechamento da cápsula articular e classificada em quatro graus, conforme os critérios de CHAUVET et al. (1996), em que grau IV representa ausência de movimento, grau III movimento de 1-2mm, grau II 3-5mm, e grau I mais que $5 \mathrm{~mm}$, o que corresponde, respectivamente, a ausente, discreto, moderado e acentuado.

Os animais foram avaliados clinicamente por 60 (grupo A) e 90 dias (grupo B), sendo que o uso funcional do membro foi determinado segundo os parâmetros citados por TUDURY \& RAISER (1985). Imagens radiográficas do joelho foram obtidas logo após a implantação, aos 60 e 90 dias de evolução. Após este período, um animal de cada grupo foi selecionado ao acaso para eutanásia, visando à avaliação da relação entre o osso doador e o osso receptor e, nos demais, foi realizada artrotomia exploratória e coleta de um segmento longitudinal de espessura equivalente a $1 / 3$ da porção ligamentar no tecido implantado. Após a recuperação pós-operatória, os animais sobreviventes foram encaminhados à doação.

As amostras obtidas foram fixadas em formol tamponado, sendo que, daquelas obtidas dos animais submetidos à eutanásia, as porções ósseas, incluindo implante e leito receptor, foram submetidas à descalcificação. Após isso, cada amostra foi processada e incluída em parafina e os cortes histológicos foram corados pela hematoxilina eosina e pelo tricrômio de Masson e examinadas sob microscopia óptica.

\section{RESULTADOS E DISCUSSÃO}

A conservação dos implantes na glicerina a 98\% por pelo menos 30 dias e o cuidado de reidratação por $24 \mathrm{~h}$ em solução salina com iodo povidine, aliados a uma intervenção cirúrgica asséptica e ao uso profilático de antibiótico, asseguraram ausência de infecção ou de sinais clínicos ou histológicos de incompatibilidade com o receptor. Os implantes foram mantidos em solução salina com povidine para serem adequadamente reidratados, pois, segundo RAISER (2000) e MAZZANTI et al. (2004), em face de suas características estruturais, o tendão demora ao redor de 24h para compensar a desidratação decorrente da conservação em glicerina. Embora se recomende o uso profilático de antibióticos por até uma semana, no uso de próteses ou implantes, o protocolo usado foi eficiente na prevenção de infecção.

No presente experimento, verificou-se, após a implantação, que o segmento articular do implante teve comprimento igual ao do ligamento original em três cães, $1 \mathrm{~mm}$ maior em seis cães, $2 \mathrm{~mm}$ maior em 12 cães e 3mm maior em outros três. Nas articulações em que o segmento articular mediu 2 ou 3mm a mais, o grau de instabilidade pós-operatória foi maior, deduzindo-se assim que o comprimento da porção intrarticular deve ser igual ou não mais que $1 \mathrm{~mm}$ além do ligamento original para manter a estabilidade. Foi observado que os animais com maior grau de instabilidade crânio-caudal no pós-operatório imediato mantiveram-na ao longo do pós-operatório, provavelmente porque o ligamento mais longo não antagonizou o movimento de deslizamento entre as superfícies articulares. O posicionamento da articulação em ângulo de $140^{\circ}$ durante a fixação do implante favoreceu a obtenção de um comprimento semelhante ao do ligamento original.

A avaliação das articulações, após a fixação do implante, indicou instabilidade crânio-caudal, que foi discreta em 18 animais e ausente nos outros seis. Na avaliação aos 60 e 90 dias de pós-operatório, detectou-se ausência do movimento de gaveta em nove dos animais, movimento discreto em doze e moderado em três. Esse grau de instabilidade pode estar relacionado ao tipo do implante utilizado, que não possui as características anatômicas do LCCr, o qual tem duas bandas que, segundo BRINKER et al. (1999), exercem efeitos antagônicos durante alternância entre flexão e extensão.

A imobilização articular nos cães deste experimento foi utilizada para proteger o implante do efeito de sobrecarga de sustentação (ANDERSON \& CONSTANTINESCU, 1998) no período inicial de pósoperatório, pois, segundo GREENWALD et al. (1995), tendões sofrem despolimerização do colágeno nas três primeiras semanas de reparação. OLIVEIRA et al. (2003), ao substituírem o LCCr de cães pelo tendão homólogo do músculo extensor digital longo, sem limitar o movimento articular, constataram que, na maioria dos pacientes, ocorreu desestabilização articular com ruptura do ligamento em $66,66 \%$ dos casos. No presente experimento, o implante manteve sua integridade em todos os cães; no entanto, a imobilização associada a sangramento do osso esponjoso, no túnel de perfuração proximal, resultou em aderências intraarticulares e em um grau considerável de rigidez articular após a retirada do aparelho de fixação esquelética externa aos 30 dias de pós-operatório. 
BEALE \& GORING (1996) citam que a imobilização prolongada impede a adequada ação bombeadora que difunde os nutrientes para o metabolismo da cartilagem. Para VANWANSEELE et al. (2002), este processo ocasiona danos à cartilagem articular. Nos cães aqui avaliados, não se verificaram lesões aos exames radiográfico e macroscópico por inspeção da articulação aos 60 e 90 dias de pós-operatório. Nesses períodos, os cães apresentaram progressivo retorno da marcha, e constatou-se espessamento da cápsula articular, resultado semelhante aos achados de OLIVEIRA et al. (2003). A porção tendínea do implante apresentava-se íntegra, espessada e de coloração esbranquiçada, semelhante ao LCCr original (Figura 2A).

A avaliação macroscópica pós-morte das porções ósseas do implante, na articulação dos dois cães submetidos a eutanásia, demonstrou que elas apresentavam-se em fase de incorporação ao osso receptor, tanto no fêmur quanto na tíbia. Aos 60 dias de pós-operatório, ainda foi possível observar os fragmentos do fio de poliéster utilizado para ancoragem do implante aos parafusos de fixação, e sua porção óssea estava delimitada no leito receptor (Figura 2B). Aos 90 dias de pós-operatório, já não foi possível distinguir as margens do fragmento ósseo do implante em relação ao leito receptor (Figura 2C). Os segmentos de tendão patelar inseridos no túnel ósseo foram facilmente identificados tanto aos 60 como aos 90 dias de pós-operatório (Figuras 2B e 2C).

Pela avaliação histológica aos 60 e 90 dias após a implantação, foram observadas fibras colágenas coradas em vermelho entre fibras coradas em azul, interdigitando-se com trabéculas ósseas (Figura 3), além da presença de vasos sangüíneos. De forma geral, as características histológicas do tendão patelar aplicado como substituto ao ligamento cruzado cranial no cão foram similares aos 60 e 90 dias de pós-operatório. A presença de novos vasos em organização zonal e de fibras colágenas coradas em vermelho é indicação de formação de novo tecido que está substituindo aquele do implante (fibras coradas em azul).

Pelos resultados obtidos, conclui-se que, na substituição do ligamento cruzado cranial por implante homólogo teno-ósseo conservado em glicerina a $98 \%$, a porção óssea é progressivamente incorporada ao leito receptor, e a porção tendínea é substituída por novas fibras colágenas, o que assegura reparação anatômica semelhante à do ligamento original.

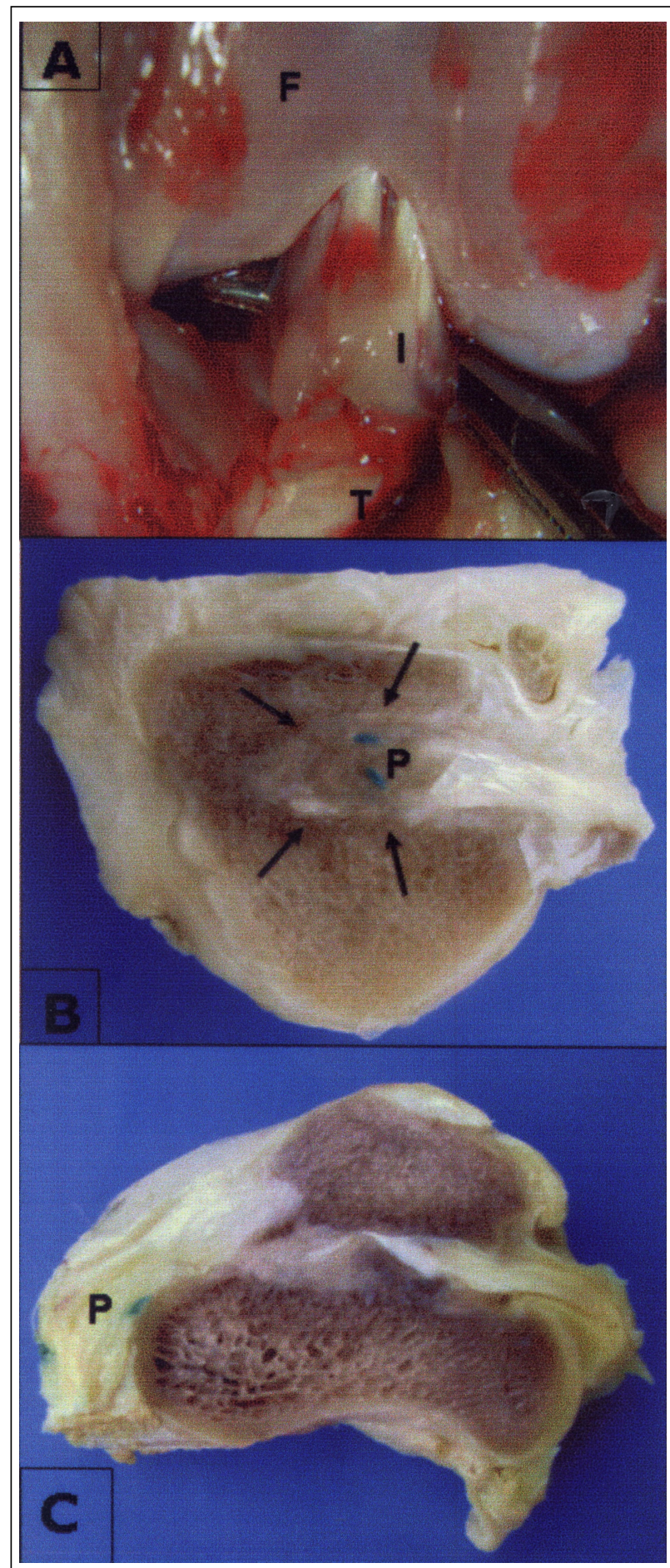

Figura 2 - (A) Implante (I) que substituiu o ligamento cruzado cranial de um cão, aos 90 dias de pós-operatório, por ocasião da biópsia ( $\mathrm{F}=$ fêmur; $\mathrm{T}=$ tíbia). Interação entre o implante com o leito receptor (setas) aos 60 dias (B) e aos 90 dias (C) da implantação. Em B e C, fragmentos do fio de poliéster $(\mathrm{P})$. 


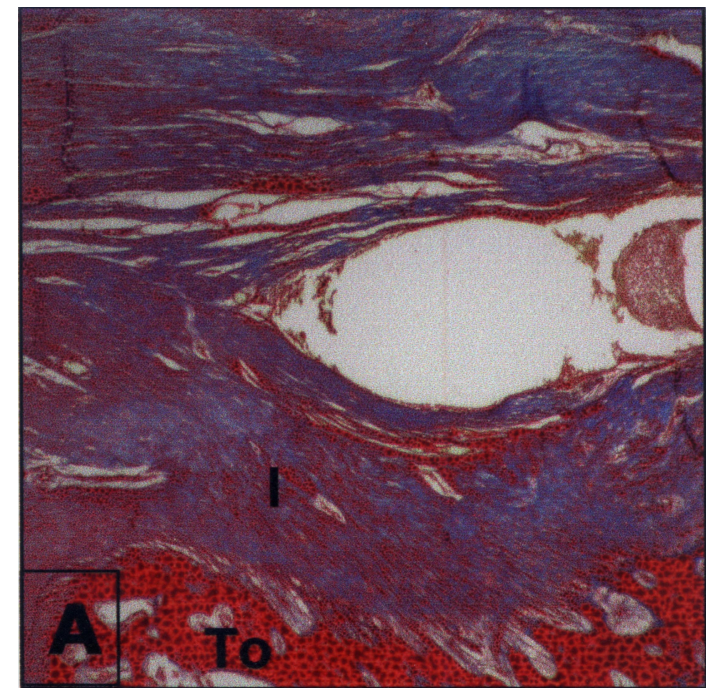

Figura 3 - Avaliação histológica do implante teno-ósseo de cão conservado em glicerina a $98 \%$, utilizado como substituto do ligamento cruzado cranial no cão. Detalhe da junção da porção óssea do implante (I) com o leito receptor aos 90 dias após implantação (To=trabécula óssea Tricrômico de Masson 40X).

\section{CONSIDERAÇÕESÉTICAS}

A pesquisa foi desenvolvida seguindo as recomendações do Colégio Brasileiro de Experimentação Animal e foi aprovado pelo comitê de ética da instituição.

\section{REFERÊNCIAS}

ANDERSON, M.A.; CONSTANTINESCU, G. Using transarticular external skeletal fixation devices. Vet Medicine, v.93, n.5, p.468-472, 1998

ANDRADE, M.A.P. et al. A repercussão da retirada do enxerto do tendão patelar no mecanismo extensor do joelho. Rev Bras Ortop, v.34, n.8, p.461-464, 1999.

ARNOCZKY, S.P. Patomecânica das lesões do ligamento cruzado e meniscos. In: BOJRAB, M.J. Mecanismos da moléstia na cirurgia dos pequenos animais. 3.ed. São Paulo: Manole, 1996. Cap.110, p.889-902.

BEALE, B.S.; GORING, R.L. Moléstia articular degenerativa. In: BOJRAB, M.J. Mecanismo da moléstia na cirurgia de pequenos animais. 2.ed. São Paulo: Manole, 1996. Cap.106, p.847-857.

BRINKER, W.O. et al. A articulação fêmuro-tíbio-patelar (joelho). In: ____ Manual de ortopedia e tratamento das fraturas dos pequenos animais. São Paulo: Manole, 1999. Cap. 17, p.480-538.

CHAUVET, A.E. et al. Evaluation of fibular head transposition, lateral fabellar suture, and conservative treatment of cranial cruciate ligament rupture in large dogs: retrospective study. J Am Anim Hosp Assoc, v.32, n.3, p.247255, 1996.

FU, F.; SCHULTE, K. Anterior cruciate ligamnet surgery 1996: state of art? Clin Orthop, v.325, n.1, p.19-24, 1996.

GREENWALD, D.P. et al. Augmented Becker versus Kesslr tenorraphy in monkeys: dynamic mechanical analiysis. J Hand Surg, v.20A, n.2, p.267-272, 1995

JACKSON, D.W.; SHALFER, R.K. Cyclops syndrome: loss of extension following intra-articular anterior cruciate ligament reconstruction. Arthroscopy, v.6, n.1, p.171-178, 1990.

MAEDA, A. et al. Anterior cruciate ligament reconstruction with multistranded autogenous tendon. Br J Sports Med, v.24, n.2, p.504-509, 1996.

MAZZANTI, A. et al. Homoimplante ortotópico conservado, associado a terapia "soft laser" na reparação tenopatelar em cão. Ciênc Rural, v.34, n.2, p.429-437, 2004.

OLIVEIRA, S.T. et al. Reparação do ligamento cruzado cranial de cães por tendão homólogo conservado em glicerina e associado a fio de náilon. Ciênc Rural, v.33, n.24, p.717723, 2003

PACCOLA, C.A.J. et al. Reconstrução do ligamento cruzado anterior com ligamento patelar. Análise comparativa do ligamento autólogo versus homólogo. Acta Ortop Bras, v.8, n.4, p.202-208, 2000.

RAISER, A.G. Homoimplante ortotópico de tendão calcâneo comum, conservado em glicerina a $98 \%$, e tratado com radiação laser Arseneto de Gálio, sob dois métodos de imobilização, em cães. 2000. 88f. Tese (Doutorado em Cirurgia) - Programa de Pós-graduação em Medicina Veterinária, Universidade Federal de Santa Maria.

TIBONE, J.E., ARTRICH, J.T. A biochemical analysis of anterior cruciate ligament reconstruction with the patellar tendon. a two years follow-up. Am J Sports Med, v.16, n.2, p.332-335, 1998.

TUDURY, E.A.; RAISER, A.G. Redução de fraturas distais do fêmur de cães, empregando dois pinos de Steinmann em substituição aos de Rush. Rev Centro de Ciências Rurais, v.15, n.2, p.141-155, 1985.

VANWANSEELE, B et al. The effect of immobilization on the characteristics of articular cartilage: current concepts and future directions. Osteoartritis Cartilage, v.10, n.5, p.408419, 2002

VASSEUR, F.B. Articulação do joelho. Ruptura do ligamento cruzado cranial. In: SLATTER, D. Manual de cirurgia de pequenos animais. 2.ed. São Paulo: Manole, 1998. Cap.137, p.2156-2160.

ZEKCER, A. et al. “Transfix”: um método de fixação femoral dos tendões flexores na reconstrução do LCA. Relato preliminar. Rev Bras Ortop, v.36, n.9, p 340-344, 2001. 